\title{
Urban poverty, inequality and industry in Nigeria
}

\begin{abstract}
Purpose: The purpose of this paper is to examine the relationship between industrial sector growth, inequalities and urban poverty reduction

Design/methodology/approach: The paper used static panel data analysis. However, the tests suggest that there are no state-specific effects; hence, the pooled panel regression techniques are used for the analysis.

Findings: The findings of the paper suggest that the industrial sector growth exert no significance on urban poverty while the urban wholesale and retail services growth is found to be substantially strong in reducing urban poverty. The results also indicate that there is no statistically significant evidence to conclude that higher incidence of urban poverty was due to the high degree of inequalities.

Research limitations/implications: This paper has provided some helpful results in understanding the heterogeneous effects of sectoral components of growth of urban poverty in the presence of high income inequalities, but the limitation of this study is that there is no disaggregated poverty and growth data on different occupational activity.

Practical implications: There is a need to expand investment in the production and export manufacturing labor-intensive sectors; this will help increase the labor absorption rate of the industry and, thus, reduce poverty in the urban areas.

Originality/value: The paper improves on previous research on poverty in Nigeria by explicitly recognizing the effects of location and inequality.
\end{abstract}

Keyword: Inequality; Urban poverty; Industry growth; Panel data analysis 